\section{Top Growth of Cultivated Tea}

In India, tea bushes (Camellia sinensis L.) are pruned and plucked to a flat horizontal surface ${ }^{1}$ the area of which can be easily estimated ${ }^{2}$, provided that the bushes are sufficiently far apart without mutually interlocking frames. This condition was maintained in a field trial in which 12 disparate populations were grown in the sun and under Albizzia chinensis trees, both with and without ammonium sulphate at the rate of $112 \mathrm{kgm}$. nitrogen per hectare ( $100 \mathrm{lb}$. per acre) per annum. The bushes were planted on the triangular system, $1.37 \mathrm{~m}$. ( $4 \frac{1}{2} \mathrm{ft}$.) apart. The surface area of the bush frame was measured immediately after the annual pruning when the bushes were 15 years old.

The populations vary from wild-type var. assamica, through various intergrades, to populations with some features of the type variety (var. sinensis). As entities, all the populations could be assigned to var. assamica, but the range of variation is sufficient to suggest that our observation may be applicable to most tea cultivated in India that does not show marked attributes of the China or type variety.

Results of the experiment is given in Table 1 in terms of surface area of the bushes, yield of plucked shoots per unit area, and top growth removed from a unit of surface area. By top growth is meant the total green weight of prunings and pluckings. The analyses refer to growth made in the twelve months preceding the area measurement.

Table 1. Camellia sinensis VAR. assamica. ANALYSIS OF VARIANCE OF BUSH AREA, YIEID PER UNIT OF AREA, AND TOP-GROWTH PER UNIT

\begin{tabular}{|c|c|c|c|c|}
\hline \multirow{2}{*}{ Source of variance } & \multirow{2}{*}{ D. $F$. } & \multicolumn{3}{|c|}{ Mean square } \\
\hline & & Area & Yield & $\begin{array}{l}\text { Top- } \\
\text { growth }\end{array}$ \\
\hline $\begin{array}{c}\text { Between block pairs } \\
\left\{\begin{array}{l}\text { Replicate } \\
J \times N\end{array}\right.\end{array}$ & $\left.\begin{array}{l}2 \\
3\end{array}\right\}$ & 0.050 & $0 \cdot 168$ & 1.069 \\
\hline $\begin{array}{l}\text { Within block pairs } \\
\text { Shade trees }(S)\end{array}$ & 1 & $2 \cdot 268^{* *}$ & $1.935^{* *}$ & $5 \cdot 895^{* *}$ \\
\hline Error & $\left.\begin{array}{l}3 \\
2\end{array}\right\}$ & 0.060 & 0.092 & 0.337 \\
\hline $\begin{array}{l}\text { Ammonium sulphate }(N) \\
\text { Populations }(J) \\
S \times N \\
J \times S \\
J \times N \\
\text { Error } \\
\text { Error }\end{array}$ & $\begin{array}{r}1 \\
11 \\
1 \\
11 \\
11 \\
11 \\
86\end{array}$ & $\begin{array}{l}2 \cdot 436^{* * *} \\
0.113^{* * * *} \\
0.864 * * * \\
0.100 \\
0.008 \\
0.015 \\
0.014\end{array}$ & $\begin{array}{l}0.408^{* * * *} \\
0.044^{* * *} \\
0.018 \\
0.012 \\
0.008 \\
0.016 \\
0.012\end{array}$ & $\begin{array}{l}5 \cdot 104^{* * *} \\
0.155 \\
1 \cdot 964 * * * \\
0.124 \\
0 \cdot 040 \\
0.145 \\
0 \cdot 150\end{array}$ \\
\hline & 14 & - & - & - \\
\hline
\end{tabular}

Bush area is expressed in sq. m., yield and top-growth in $\mathrm{kgm}$. per sq. $m$. Significance at 5,1 and 0.1 per cent levels are indicated by one, two and three asterisks respectively.

Top growth per unit area of bush surface is statistically the same for all populations showing that when the bushes are spaced sufficiently far apart for the differential development of their frames (Table 1), then the green weight of top growth removed from a unit area of ground covered by the frames is a constant for all populations. On the same basis, yield of plucked shoots which is the commercially important fraction of the top growth, differs between populations. This shows that a partition of growth between prunings and pluckings is a factor of importance in the agronomics of tea.

Further details of the crop yield of disparate populations will be given in a fortheoming publication ${ }^{3}$ by Dr. W. Wight, to whom the author is indebted for the data presented in this communication.

Tocklai Experimental Station,

D. N. Barva

Cinnamara, Assam.

'Wight, W., and Barua, D. N., J. Exp. Bot., B, 1 (1955).

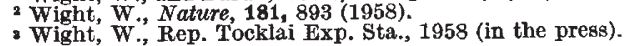

\section{ENTOMOLOGY}

\section{Survival of Grasshopper Eggs Kept for Long Periods in Mineral Oil}

THE ease with which diapause may be broken in the eggs of a common North American grasshopper, Melanoplus differentialis differentialis (Thomas), with mineral (paraffin) oil has been described recently ${ }^{1}$. Treatment with the oil for $1 \mathrm{hr}$. or less is sufficient to remove the waterproofing materials from the hydropyle. After the eggs are taken from the oil, cleaned and transferred to a medium from which they can absorb water, development begins and they hatch in a completely normal manner about 18 days later. No harmful effect of the oil on the eggs can be detected even if they are left in it for as long as four weeks.

After the series of experiments reported in $1958 \mathrm{had}$ been completed, 153 eggs from a single pod laid 15 days earlier and incubated at $25^{\circ} \mathrm{C}$. since that time were dried briefly, placed in a Petri dish containing a thin film of mineral oil and returned to the incubator. The chorion was left intact. Six months later 103 of these eggs were selected and the chorion removed from each. They were freed from oil and placed to incubate on cotton-wool moistened with Ringer's solution which had been diluted with an equal volume of distilled water. During the three weeks. which followed nine eggs spoiled and three were lost accidentally. All but one of the remaining eggs completed blastokinesis and 74 of them hatched. The nymphs behaved and grew to maturity exactly as do grasshoppers which develop in eggs kept under ordinary conditions. The percentage which hatched and that which completed nymphal development both lie well within the range commonly obtained when eggs are incubated in damp sand for six months at $25^{\circ} \mathrm{C}$. Metabolic activity proceeds at a reduced rate when development is suspended ${ }^{2}$; but the supply of yolk gradually diminishes ${ }^{3}$ and after six months the amount remaining in a particular egg may be insufficient to produce a viable nymph. In addition, waste products accumulate and the fat body becomes heavily laden with urate crystals.

When the eggs were examined after having been in mineral oil for six months it was observed that a light growth of fungus had appeared on the chorion of some of them and that a sharp, rancid odour reminiscent of butyric acid was noticeable. The 50 eggs left after the removal of the group of 103 were placed in fresh mineral oil and transferred to a clean container to discover whether any would survive an even longer period in the oil. Similar transfers were made at approximately 4 -week intervals thereafter but mould re-appeared following each transfer and it seemed probable that all of the eggs would be killed. During the second 6-month period, 12 of the eggs showed obvious signs of decomposition and were discarded. At the end of one year in the oil the chorion was removed from each of the remaining $38 \mathrm{eggs}$ and all were cleaned and placed to incubate on moist cotton. Within a few days rhythmic movements of the lateral body walls proved that the embryos in 20 of the eggs were still alive and that development had been resumed. Fourteen of these completed blastokinesis and seven of them hatched. Seven others completed embryonic development but failed to hatch. The rest died earlier. As this is written the first grasshopper to hatch is a vigorous sixth instar nymph. If some effective means of stopping the growth of mould had been employed it seems possible that a considerably larger number of eggs would have survived and hatched. 